Удк 632.928

\title{
КОРРЕЛИРОВАНИЕ СОДЕРЖАНИЯ АСКОРБИНОВОЙ КИСЛОТЫ В АССИМИЛЯЦИОННОМ АППАРАTЕ BETULA PENDULA ROTH. С ДЕЙСТВИЕМ ПАТОЛОГИЧЕСКОГО АГЕНТА
}

\section{() М.Э. Баландайкин}

\author{
Ульяновский государственный университет, ул. Л. Толстого, 42, \\ Ульяновск,432017 (Россия), e-mail: 131119892007@rambler.ru
}

Рассматриваются особенности влияния совокупности антропогенных факторов и фитопатологического состояния дерева Betula pendula на концентрацию аскорбиновой кислоты в ассимиляционном аппарате. По критерию воздействия Inonotus obliquus (Pers.: Fr.) Pilat и присугствию поллютантов оценивалась адаптационная способность растения к действию стрессоров, а также возможность выработки механизмов, отвечающих за ингибирование биосинтеза аскорбиновой кислоты.

Показано, что из всех проанализированных в данной работе абиотических и биотических факторов наиболее существенно на изменении концентрации аскорбиновой кислоты в листовых пластинках деревьев относительно нормы сказывается патогенный фактор.

Ключевые слова: Inonotus obliquиs (Pers.: Fr.) Pilat, Betula pendula Roth., аскорбиновая кислота.

\section{Введение}

Одним из показателей фотосинтетических процессов и благополучного произрастания растений являются вторичные метаболиты. Неблагоприятные экологические условия снижают фотосинтез растений и повышают дыхание и траты запасных веществ на выживание, вследствие этого происходит снижение содержания многих вторичных метаболитов, в том числе аскорбиновой кислоты [1].

Аскорбиновая кислота - уникальное полифункциональное соединение [2-5]. Она принимает участие в процессах роста, цветения, вегетативной и репродуктивной дифференциации, в водном обмене, регуляции ферментативной активности, стимуляции реакций метаболизма, связанных с обменом нуклеиновых кислот и синтезом белка, в защитных реакциях растений [4].

I. obliquus вызывает гнилевое заболевание дерева, которое сопровождается нарушением физиологических функций, изменением гистологической структуры вегетативных органов и снижением продуктивности растения. Поэтому при возникновении грибной инфекции у питающего растения изменяются биохимические и физиологические показатели жизнедеятельности различных вегетативных органов, например интенсивность биосинтеза и концентрация ряда метаболитов в фотосинтетическом аппарате, некоторые анатомо-морфологические характеристики последних.

Вопрос о влиянии разнообразных инфекционных болезней на концентрацию аскорбиновой кислоты в ассимилирующем аппарате питающих растений изучен недостаточно [6-8], что обусловливает необходимость осуществления подобных исследований.

Цель настоящей работы - изучить особенности воздействия различных биоэкологических факторов, и в первую очередь фитопатогенного, на содержание аскорбиновой кислоты в листовых пластинах березы.

\section{Экспериментальная часть}

Баландайкин Михаил Эдуардович - аспирант кафедры лесного хозяйства, экологического факультета института медицины, экологии и физической культуры, e-mail: 131119892007@ rambler.ru
Содержание аскорбиновой кислоты в листьях определялось по методике И.К. Мурри [9].

Пробы листьев для эксперимента отбирались из верхней третьей части кроны в сухую погоду, 
в утренние часы, после высыхания росы. Средняя проба отдельного дерева формировалась из разделенных по средней жилке половинок 10 листьев. Каждая выборка содержала по 7 экземпляров деревьев. Сбор материала производился после остановки интенсивного роста листьев (начиная с июля), что связано с достижением зрелости большинством листьев дерева. Работа была выполнена на территории Барышского участкового лесничества Ульяновской области.

Содержание аскорбиновой кислоты выражалось в миллиграммах вещества на 100 г сырого веса (мг\%) и было равно

$$
(X \cdot A \cdot V \cdot 100) /(d \cdot H)
$$

где $X$ - поправочный коэффициент (показывает количество аскорбиновой кислоты (мг), соответствующее $1 \mathrm{~cm}^{3}$ приготовленной краски); $A$ - объем краски, пошедший на титрование, $\mathrm{cm}^{3} ; V-$ общий объем растительного экстракта, см ${ }^{3} ; d$ - объем гомогената, взятого на титрование, $\mathrm{cm}^{3} ; H$ - навеска, г.

Принадлежность результатов измерений к нормальному распределению не проверялась, так как $\mathrm{n} \leq 15$ [10]. Статистическая обработка данных осуществлялась методом попарных сравнений, допускающим проведение математического анализа сравниваемых выборок по параметрам нормального распределения либо распределения Стьюдента в физиологических и биохимических исследованиях благодаря возможности сопоставления пар измерений [5]. В биологических опытах считается достаточным 5\% уровень значимости (вероятность ошибочной оценки $\mathrm{P}=0,05$ ) [11].

Средняя квадратичная ошибка различий, наблюдаемых между парными вариантами, устанавливалась по корню соотношения:

$$
m_{d}=\sqrt{\left(\left(\sum d^{2} / n\right)-D^{2}\right) /(n-1)},
$$

где $\mathrm{d}$ - разница между парными значениями сравниваемых величин; D - различие средних сравниваемых совокупностей. Величина $\mathrm{t}$, следующая $\mathrm{t}$-статистике Стьюдента, рассчитывалась по формуле: $\mathrm{t}=\mathrm{D} / \mathrm{m}_{\mathrm{d}}$. Вносилась поправка Бонферрони.

\section{Обсуждение результатов}

Обработанные с помощью методов математической статистики результаты эксперимента занесены в таблицу.

Критическое значение t с частичной поправкой Бонферрони, модификация критерия Стьюдента для множественных сравнений с одной группой составляет 4,00 $(0,0071,6)$. В общем случае оно равно 5,33 $(0,0018,6)$, при простом парном сравнении - 2,45 $(0,05,6)$. Следовательно, опытная совокупность, представленная пораженными трутовиком скошенным экземплярами деревьев, статистически достоверно отличается от здоровой березы повислой, произрастающей в лесонасаждении, по содержанию аскорбиновой кислоты в листьях $(\mathrm{t}=18,83)$.

По концентрации аскорбиновой кислоты в листовых пластинках B. pendula Roth. здоровые экземп-

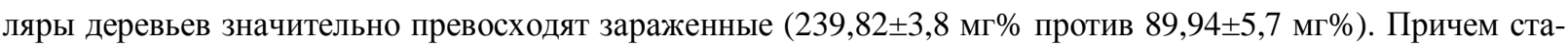
тистические показатели: ошибка и математическое ожидание - коррелируют отрицательно.

Содержание аскорбиновой кислоты в листьях березы, формирующей различные биотопы Барышского

\begin{tabular}{|c|c|c|c|c|c|c|c|c|}
\hline \multirow[b]{2}{*}{$\begin{array}{l}\text { Концентра- } \\
\text { ция аскор- } \\
\text { биновой } \\
\text { кислоты, } \\
\text { мг\%; ос- } \\
\text { новные } \\
\text { статистики }\end{array}$} & \multirow[b]{2}{*}{$\begin{array}{c}\text { Больные деревья } \\
\text { березы повислой } \\
\text { в насаждении } \\
\text { без дифференциа- } \\
\text { ции по стадиям раз- } \\
\text { вития чаги }\end{array}$} & \multicolumn{7}{|c|}{ Здоровые деревья березы в различных биотопах } \\
\hline & & 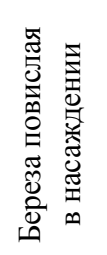 & 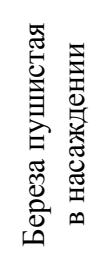 & 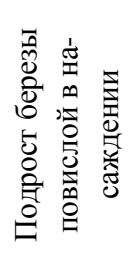 & 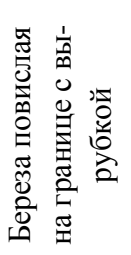 & 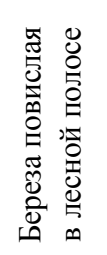 & 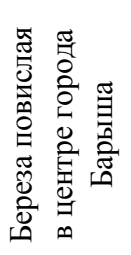 & 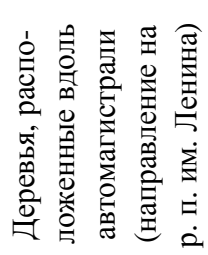 \\
\hline $\bar{x}$ & 89,94 & 239,82 & 237,12 & 235,17 & 243,07 & 247,09 & 251,31 & 247,28 \\
\hline$s$ & 15,08 & 10,05 & 19,31 & 10,32 & 15,08 & 14,02 & 11,38 & 8,20 \\
\hline$s_{\bar{x}}$ & 5,7 & 3,8 & 7,3 & 3,9 & 5,7 & 5,3 & 4,3 & 3,1 \\
\hline $\mathrm{t}$ & 18,83 & - & 0,33 & 0,73 & 0,47 & 1,10 & 1,72 & 1,31 \\
\hline
\end{tabular}
участкового лесничества 
Довольно часто в специальной литературе сообщается об активации биосинтеза аскорбиновой кислоты растениями в ответ на воздействие стресс-факторов различного происхождения. Таким образом, подчеркивается антистрессовая роль рассматриваемого ассимилянта $[12,13]$. Однако стимуляции продуцирования аскорбиновой кислоты в отношении влияния трутовика скошенного на березу повислую не наблюдается. Подобный факт, очень вероятно, может объясняться, по крайней мере, двумя причинами. Вопервых, непосредственно обнаружить плодовые тела I. obliquus и пораженные участки древесины на ранних этапах развития патогена очень трудно, поскольку в первую фазу онтогенеза базидиальный макромицет бывает прикрыт корой дерева. Наблюдать моменты выхода гриба из-под коры - чрезвычайно большая редкость [14]. Во-вторых, до появления грибницы и начала развития экзогенного стерильного мицелия $I$. obliquus, образующего на коре характерные наросты, проходит около трех лет [15-17]. Так как гнилевое заболевание березы, вызванное трутовиком скошенным, носит активно развивающийся характер [14, 18, 19], следует предположить, что за это время ксилолитический процесс приводит к значительной дестабилизации состояния гомеостаза растения-хозяина, сопровождающейся ослаблением сопротивления организма фитопатологическому стрессору. А первичная стрессовая реакция растительного организма на стрессор (по Г. Селье, фаза тревоги) уже прошла. Поэтому на данном этапе не отмечается повышения содержания аскорбиновой кислоты в листовых пластинах инфицированных трутовиком скошенным деревьев относительно здоровой березы повислой. Предполагаемое активирование биосинтеза аскорбиновой кислоты, вероятнее всего, могло происходить на начальных стадиях развития макробазидиомицета на стволе дерева исходя из представлений, согласно которым аскорбиновая кислота способна оказывать воздействие на иммунные свойства растений - одним из проявлений их активного иммунитета является нормальное или повышенное образование в листьях аскорбиновой кислоты $[4,12]$.

Из таблицы следует, что в листьях березы повислой, испытывающей негативное воздействие на аппарат ассимиляции со стороны автотранспортных эмиссий загрязняющих атмосферный воздух веществ, прослеживается увеличение концентрации аскорбиновой кислоты по сравнению с содержанием данного метаболита в листьях березы, произрастающей в более благополучной среде. Содержание аскорбиновой кислоты в листовых пластинках возрастает с усилением интенсивности потока автотранспорта и, следовательно, увеличением выбросов выхлопных газов в атмосферу. У здоровой березы повислой, расположенной в центральном городском биотопе, концентрация аскорбиновой кислоты в листьях больше, чем у березы из лесопосадок, которые граничат с автомагистралью на рабочий поселок им. Ленина, и здоровых де-

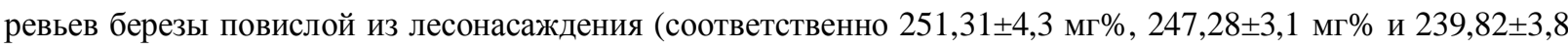
мг\%). В центре города Барыша интенсивность автопотока выше, нежели за его пределами, - магистраль на рабочий поселок им. Ленина.

Хотя наблюдается увеличение концентрации аскорбиновой кислоты в листовых пластинах по мере повышения уровня техногенных нагрузок, нельзя считать эту связь строго детерминированной. Увеличение содержания аскорбиновой кислоты в паренхиме мезофилла листьев $B$. pendula, произрастающей в центре города Барыша, на 4,79\% относительно концентрации аскорбиновой кислоты в листьях здоровых деревьев березы повислой, формирующей насаждение, и на 1,68\% по сравнению с концентрацией аскорбиновой кислоты в листьях деревьев у трассы на р. п. им. Ленина обусловливается и различной степенью конкуренции в биотопах. В насаждениях ярко выражена внутривидовая конкуренция за радиационные, трофические, гидротермические и прочие ресурсы. В центре Барыша береза, напротив, не образовывает парков. Вследствие разреженного размещения деревьев по площади в биотопах городской среды повышается общая доступность фотосинтетически активной радиации, которая в ряде работ отечественных и зарубежных авторов рассматривается как немаловажное условие для катализа биосинтеза аскорбиновой кислоты через усиление активности фотосинтетического процесса. Увеличение концентрации аскорбиновой кислоты в листьях у березы повислой с повышением техногенной нагрузки подтверждают А.Н. Журавлева, И.Л. Бухарина и А.А. Двоеглазова [13]. Помимо всего прочего, эти авторы отмечают чрезвычайно высокую изменчивость содержания аскорбиновой кислоты в листовых пластинках, обеспечивающую березе повислой экологическую пластичность.

Как свидетельствует таблица, в листовых пластинах подроста березы повислой из лесонасаждения аскорбиновой кислоты содержится меньше, нежели в листьях более высоких доминирующих здоровых деревьев березы повислой, формирующей насаждение. Концентрация аскорбиновой кислоты в листьях подроста составляет $235,17 \pm 3,9$ мг\%, содержание анализируемого ассимилянта в листьях здоровой березы повислой в насаждении достигает 239,82 3,8 мг\%. Вероятно, подобное может быть связано с тем, что содержание аскорбиновой кислоты больше бывает в листьях верхних ярусов, чем нижних. 


\section{Bыводbl}

1. Ксилотрофный базидиомицет трутовик скошенный при доверительной вероятности 0,95 статистически достоверно обусловливает существенное снижение содержания аскорбиновой кислоты в ассимиляционном аппарате березы повислой.

2. Результаты предлагаемой работы по анализу влияния трутовика скошенного на витальность березы повислой показали, что фитопатологические агенты следует рассматривать в качестве одного из самых сильных стрессовых факторов питающего растения-хозяина.

3. Концентрация аскорбиновой кислоты в листьях березы определяется комплексным воздействием на нее со стороны биоэкологических факторов.

\section{Список литературы}

1. Колмогорова Е.Ю. Интенсивность синтеза вторичных метаболитов в хвое сосны обыкновенной, произрастающей в условиях породного отвала угольного разреза «Кедровский» // Экологические проблемы промышленных городов: сборник научных трудов / под ред. Е.И. Тихомировой. Саратов, 2011. Ч. 2. С. 127-129.

2. Шапиро Д.К. Практикум по биологической химии. Минск, 1972. 288 с.

3. Петров К.П. Методы биохимии растительных продуктов. Киев, 1978. 224 с.

4. Чупахина Г.Н. Система аскорбиновой кислоты растений : монография. Калининград, 1997. 120 с.

5. Чупахина Г.Н. Физиологические и биохимические методы анализа растений. Калининград, 2000. 59 с.

6. Побегайло А.И., Ладейщикова Е.И., Белый Г.Д. Физиологические особенности сосны в условиях поражения ее корневой губкой // Лесоводство и агролесомелиорация. Киев, 1969. Вып. 17. С. 88-96.

7. Негруцкий С.Ф. Корневая губка. М., 1986. 195 с.

8. Чураков Б.П. Взаимоотношения патогенных грибов с древесными растениями. М., 1993. 195 с.

9. Практикум по агрохимии / под ред. В.Г. Минеева. М., 2001. 689 с.

10. ГОСТ 8.207-76. Прямые измерения с многократными наблюдениями. Методы обработки результатов измерений. 8 с.

11. Лакин Г.Ф. Биометрия. М., 1990. 352 с.

12. Чупахина Г.Н., Романчук А.Ю., Платунова Е.В. Аскорбиновая кислота как антистрессовый фактор растений // Интродукция, акклиматизация и культивация растений : сб. науч. трудов. Калининград, 1998. С. 88-94.

13. Журавлева А.Н., Бухарина И.Л., Двоеглазова А.А. Экологическое состояние почв и динамика антиоксидантов в побегах древесных растений в насаждениях г. Ижевска // В мире научных открытий. 2011. №5. С. 297-306.

14. Бондарцев А.С. Труговые грибы Европейской части СССР и Кавказа. М.; Л., 1953. 1106 с.

15. Сурков В.А., Павлова М.Э. Экологические группы грибов. М., 1998. 27 с.

16. Саакян К.Р., Ващенко К.Ф., Дармограй Р.Э. Чага (черный березовый гриб). Аналитический обзор // Провизор. 2004. №16. С. 56.

17. Шашкина М.Я., Шашкин П.Н., Сергеев А.В., Горяйнова Л.К. Чага, чаговит, чагалюкс в лечебной и профилактической практике. М., 2009. 66 с.

18. Синадский Ю.В. Береза. Ее вредители и болезни. М., 1973. 217 с.

19. Бондарцева М.А., Пармасто Э.Х. Определитель грибов СССР: Порядок афиллофоровые. Вып. 1. Семейства гименохетовые, лахнокладиевые, кониофоровые, щелелистниковые. Л., 1986. 192 с.

Поступило в редакиию 4 октября 2012 г.

После переработки 1 февраля 2014 г. 


\section{Balandaykin M.E. CORRELATION OF CONTENT ASCORBIC ACID IN THE ASSIMILATION APPARATUS BETULA PENDULA ROTH. WITH AGENT BY PATHOLOGICAL}

Ulyanovsk State University, L. Tolstogo st., 42, Ulyanovsk, 432017 (Russia), e-mail: 131119892007@rambler.ru

Features of influence of set of anthropogenic factors and phytopathologic state of tree Betula pendula on concentration of ascorbic acid in it assimilation apparatus are considered. By criterion of influence Inonotus obliquus (Pers.: Fr.) Pilat and to presence pollution adaptable ability of a plant to action stressful factors, and also possibility of development of the mechanisms which are responsible for inhibition of biosynthesis of ascorbic acid estimated.

It is shown that from all analysed in the yielded work abiotic and biotic factors most essentially the pathogenic factor affects change of concentration of ascorbic acid in sheet plates of trees concerning norm.

Keywords: Inonotus obliquus (Pers.: Fr.) Pilat, Betula pendula Roth., ascorbic acid.

\section{References}

1. Kolmogorova E.Iu. Ekologicheskie problemy promyshlennykh gorodov: sbornik nauchnykh trudov. [Ecological problems of industrial cities: collection of scientific papers]. Ed. E.I. Tikhomirova. Saratov, 2011, part. 2, pp. 127-129. (in Russ.).

2. Shapiro D.K. Praktikum po biologicheskoi khimii. [Workshop on Biological Chemistry]. Minsk, 1972, 288 p. (in Russ.).

3. Petrov K.P. Metody biokhimii rastitel'nykh produktov. [Methods of biochemistry of plant products]. Kiev, 1978, 224 p. (in Russ.).

4. Chupakhina G.N. Sistema askorbinovoi kisloty rastenii. [System ascorbic acid plants]. Kaliningrad, 1997, 120 p. (in Russ.).

5. Chupakhina G.N. Fiziologicheskie i biokhimicheskie metody analiza rastenii. [Physiological and biochemical methods of plant analysis]. Kaliningrad, 2000. 59 p. (in Russ.).

6. Pobegailo A.I., Ladeishchikova E.I., Belyi G.D. Lesovodstvo i agrolesomelioratsiia, Kiev, 1969, no. 17, pp. 88-96. (in Russ.).

7. Negrutskii S.F. Kornevaia gubka. [Root sponge]. Moscow, 1986, 195 p. (in Russ.).

8. Churakov B.P. Vzaimootnosheniia patogennykh gribov $s$ drevesnymi rasteniiami. [Pathogenic fungi relationship with woody plants]. Moscow, 1993, 195 p. (in Russ.).

9. Praktikum po agrokhimii. [Workshop on Agricultural Chemistry]. Ed. V.G. Mineev. Moscow, 2001, 689 p. (in Russ.).

10. GOST 8.207-76. Priamye izmereniia s mnogokratnymi nabliudeniiami. Metody obrabotki rezul'tatov izmerenii. [State Standard 8.207-76. Direct measurements with multiple observations. Methods of processing measurement results]. (in Russ.).

11. Lakin G.F. Biometriia. [Biometrics]. Moscow, 1990, 352 p. (in Russ.).

12. Chupakhina G.N., Romanchuk A.Iu., Platunova E.V. Introduktsiia, akklimatizatsiia i kul'tivatsiia rastenii: Sb. nauch. trudov. [Introduction, acclimatization and cultivation of plants: Collection of scientific papers]. Kaliningrad, 1998, pp. 88-94. (in Russ.).

13. Zhuravleva A.N., Bukharina I.L., Dvoeglazova A.A. V mire nauchnykh otkrytii, 2011, no. 5, pp. 297-306. (in Russ.).

14. Bondartsev A.S. Trutovye griby Evropeiskoi chasti SSSR i Kavkaza. [Trutovyh mushrooms European part of the USSR and the Caucasus.]. Moscow; Leningrad, 1953, 1106 p. (in Russ.).

15. Surkov V.A., Pavlova M.E. Ekologicheskie gruppy gribov. [Environmental groups fungi]. Moscow, 1998, 27 p. (in Russ.).

16. Saakian K.R., Vashchenko K.F., Darmograi R.E. Provizor, 2004, no. 16, p. 56. (in Russ.).

17. Shashkina M.Ia., Shashkin P.N., Sergeev A.V., Goriainova L.K. Chaga, chagovit, chagaliuks $v$ lechebnoi i profilakticheskoi praktike. [Chaga chagovit, chagalyuks in curative and preventive practices]. Moscow, 2009,66 p. (in Russ.).

18. Sinadskii Iu.V. Bereza. Ee vrediteli i bolezni. [Birch. Her pests and diseases]. Moscow, 1973, 217 p. (in Russ.).

19. Bondartseva M.A., Parmasto E.Kh. Opredelitel' gribov SSSR: Poriadok afilloforovye; Vyp. 1. Semeistva gimenokhetovye, lakhnokladievye, konioforovye, shchelelistnikovye. [Determinant of the fungi of the USSR: Order afilloforovye; issue. 1. Gimenohetovye family, lahnokladievye, konioforovye, schelelistnikovye]. Leningrad, 1986, 192 p. (in Russ.). 
